\title{
Research
}

\section{Bee flora in mid hills of Central Nepal}

\author{
Subodh Adhikari ${ }^{1+\star}$ and Nar B. Ranabhat ${ }^{2}$ \\ ${ }^{1}$ Amrit Campus, Tribhuvan University, Kathmandu, Nepal; ${ }^{2}$ University of Hohenheim, 70593; Stuttgart, Germany \\ ${ }^{\dagger}$ Current address: Wichita State University, 1845 Fairmount, Wichita, KS 67260, USA
}

\begin{abstract}
Beekeeping is one of the promising ventures for economically poor families in Nepal. Knowledge about the bee flora of a certain area is very crucial for the farmers. A study was conducted in mid hills of Central Nepal during 2003-04 and 2008-09 to monitor the common plant species visited by bees with their visiting time and seasons. The flowering period of those plant species were also observed. Observations were made on the bees' activities on flowers of different plant species. Relevant information was also collected through informal key informant interviews. The plant species visited by the bees and the bee species (mainly Apis cerena with some Apis melifera) themselves were collected, preserved and identified. Plants were categorized as major, medium and minor sources of pollen and/or nectar. The pollen and nectar statuses in different plants were also determined. A total of 158 plant species were identified as main bee flora in the study area. Among them, 19 species were horticultural plants, 42 species were crop plants, 15 species were ornamental plants and 82 species were wild plants. In total, 38 species were recognized as major, 35 as medium and 30 as minor sources for both nectar and pollen. Months from March to May and August to October were the honey flow periods. Species of Brassica, Citrus, Pyrus, Berberis, Rubus, Callistemon, Bombox and Artemisia were some of the important plants which bloomed during those months. Winter (mid November to January) and rainy (June and July) seasons were identified as the dearth periods for bees to collect honey. Some of the plants that bloom during winter were Pisum sativum, Ipomoea batata and Eupatorium sp. Similarly, Lagerstroemia sp., Impatiens balsamina, Sesamum indicum, Zea mays and many cucurbits bloomed during rainy season. Study has shown that mid-hills of Central Nepal is rich in bee flora and has great potential for beekeeping as many plants bloomed even in dearth periods.
\end{abstract}

Key-words: beekeeping, dearth period, Honey flow, honey dew, nectar source, pollen source

\section{Introduction}

Beekeeping is one of the promising ventures for economically poor families in Nepal. Owing to massive geographical variations enriched with biodiversity, several species of bees have been noticed (Joshi 1999). Similarly, the quality of the honey produced depends on the seasons and timing of the bees visiting diverse plant species. Many of the farmers engaged in beekeeping enterprise since long times have

*Correspondence,

e-mail: subodh.adhikari1@gmail.com, tel: 01-316-347-6753 enriched indigenous knowledge on plant species and quality of honey (Ranabhat 2010).

Bee floras are the major sources of nectar and pollen for the bees (Partap 1997). Knowledge about the bee flora of a certain area is very crucial for the beekeepers (farmers). Considerable research has been carried out in improved production of crops and fruits. However, the major aspect of crop production, the pollination system of bee flora, has been neglected. Pollination is even more important than quality of seeds, fertilizer and irrigation for better and higher production (Joshi 1999; Adhikari 2003). Bee pollination not only helps to produce seeds but also enhances quality and yield of seeds 
and fruits of bee flora (Joshi 1999). Decline in fruits and seed production of different important plant species in the Hindukush Himalayan Region has been reported due to the decline of bee pollinators (Partap 1997; Partap and Partap 2001). About one third of the total human diet comes from bee pollinated crops and pollination value worth about 143 times more than honey production (Mishra 1989). Average global value of pollination system is $\$ 117 \mathrm{ha}^{-1} \mathrm{yr}^{-1}$ (Costanza et al. 1997). Bee floras and their pollinators are greatly affected by environmental variables (Kearns and Inouye 1993). Flower development and opening, nectar secretion, anther dehiscence and seed development are all dependent on ambient temperature. Similarly, air temperature affects the activity of flower-visitors. Bees, the most important pollinators, can't go outside their hive in cold, foggy and rainy weathers (Adhikari 2003, 2010). Some evolutionary co-adaptation can also be seen between flowers and their bee pollinators (Macior 1990, Macior and Ya 1997). The present study was carried out to identify the existing bee flora and to prepare floral calendar for central region of Nepal.

\section{Materials and Methods}

\section{STUDY AREA}

This study was carried out during 2003 to 2004 in areas of three Village Development Committees (VDCs) of Kaski District $\left(83^{\circ} 40^{\prime}\right.$ to $84^{\circ} 12^{\prime}$ longitude and $28^{\circ} 06^{\prime}$ to $28^{\circ} 36^{\prime}$ latitude) viz. Kristi Nachne Chour, Nirmal Pokhari and Pumdi Bhumdi, and during 2008 to 2009 in areas of three VDCs of Lamjung District ( $82^{\circ} 41^{\prime}$ longitude and $28^{\circ} 23^{\prime}$ latitude) viz. Duradanda, Chandreswor and Neta. The altitude of the study area in Kaski ranges from 840 to $1525 \mathrm{~m}$ above mean sea level (m asl) and in Lamjung from 1050 to $1560 \mathrm{~m}$ asl (Ranabhat 2010). This altitudinal variation has created the environmental heterogeneity and ultimately the variation in biodiversity, especially the large varieties of flowering plants in different seasons. The climate is monsoonal. Normally, the monsoon begins in the month of June and attains a maximum in July. Kaski district receives the highest rainfall among all other districts of Nepal. About $70 \%$ of the annual rainfall takes place during the rainy season from June to August (Figure 1). The period September to November is dry and warm, December to February is cold and March to June is dry and hot (Figure 2). The climate in these regions is strongly influenced by the Annapurna Range with Mount (Mt.) Annapurna (8091 m asl), Mt. Machhapuchhre (6993 m asl), Mt. Dhaulagiri (8167 m asl) and Mt. Lamjung (6983 m asl) (NTB 2010).

\section{METHODS}

The first field data were collected during September, October and December of 2003, and January, April and May of 2004; the second field data were collected during June, July, August and November of 2008, and February and March of 2009. Field data were collected through survey, which included observation of bees' activities on flowers of different plant species, and the collection and preservation of plant and bee

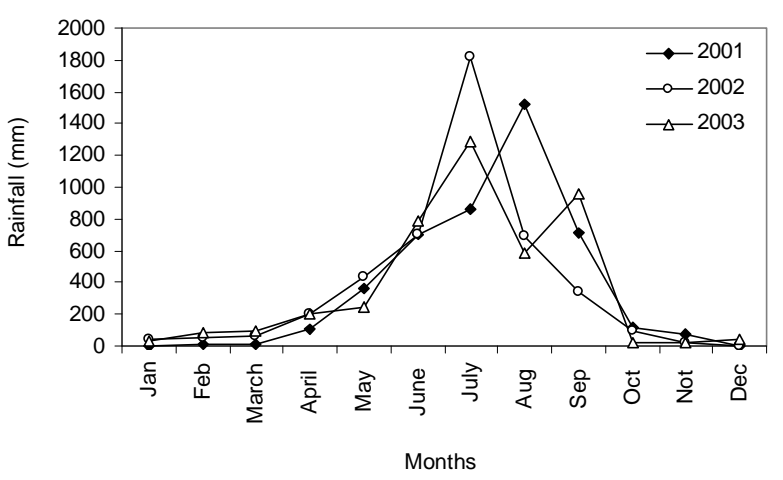

Figure 1. Rainfall measured during the different months taken consecutively for three years (2001 to 2003) (source: DHM 2004).

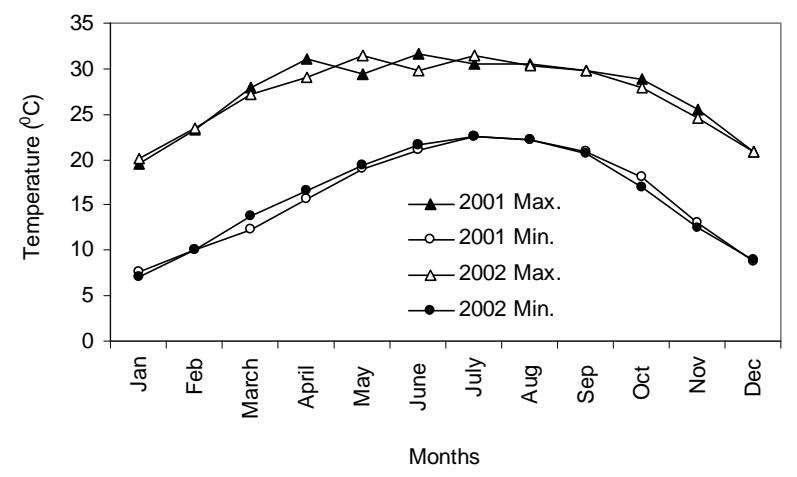

Figure 2. Temperature during the different months taken consecutively for three years (2001 to 2003) (source: DHM 2004). 
specimens. The specimens of plants were identified at Tribhuvan University Central Herbarium (TUCH), and the specimens of bees at the Central Department of Zoology and Natural History Museum of Tribhuvan University, Kathmandu Nepal. The location of hive and the surrounding flora were also examined. The major bee foraging plants were further verified by direct observation. The foraging plants were marked and observed on three seasons in Sep/Oct, Dec/ Jan, April/May and Jun/July. The observations on nectar and pollen source were based on activities performed by honeybees on different flowers. The flowers where the honey bees extended their proboscis into the deep region were considered as sources of nectar, and the flower on which bees were observed with pollens on their hind legs were considered as sources of pollens (Bista and Shivakoti 2000-2001). Honeydew plants were considered to those plants from which honey bees collected propolis (a waxy resinous substance that comes from buds and useful in making bee hive).

The sources and their status were determined by the time invested by bees on the flowers $(<5$ seconds or $5-20$ seconds or $>20$ seconds), frequency of bees' visits ( $<2$ times/ 30 minutes or 2-5 times/30 minutes or $>5$ times/30 minutes) and flowering duration (time up to when a flower blooms) of source plant ( $<2$ days or 2-5 days or $>5$ days). The plant species were categorized into major (designated as N1P1), medium (N2P2) and minor (N3P3) sources of pollen and/or nectar depending upon their resource potentials (presence and abundance of pollen, nectar and honeydew).

Additional information like most visited plant species by bees and their flowering time were obtained from the beekeepers of the nearest village through interview with structured questionnaire individually. Ninety beekeepers (50 from Kaski and 40 from Lamjung), out of total 230, were randomly selected and interviewed.

\section{Results}

\section{NECTAR AND POLLEN SUPPLY}

The plant species were mostly visited by Apis cerena with some Apis melifera. A total of 158 plant species were identified as important bee flora in the study area. Among them, 76 plant species were cultivated (19 horticultural species, 42 crop species and 15 ornamental species) and 82 species were wild (Table 1). Out of 158, 38 species were recognized as the major (N1P1), 35 as medium (N2P2) and 30 as minor (N3P3) sources for both nectar and pollen. Similarly, 52 species were identified as major sources of nectar (N1), 52 medium (N2) and 44 minor (N3). Similarly, 54 species were identified as major sources of pollen (P1), 54 medium (P2) and 48 minor (P3) (Table 1). Out of 158 species, plants having both nectar and pollen with their same status (i.e. N1P1, N2P2 and N3P3) were more $(65.19 \%)$ than the plants having unequal status (N1P2, N1P3, N2P1, N2P3, N3P1 and N3P2) of pollen and nectar. N1P1 (major pollen and nectar sources) was found to be proportionately higher in horticultural plants (57.89\%) than in other plants (23.81\% in crops, $13.33 \%$ in ornamental and $18.29 \%$ in wild species). Similarly, N2P2 (medium sources) was proportionately higher in wild plants (26.83\%) than in other plants (20\% in ornamentals, $19.05 \%$ in crops, and $10.53 \%$ in horticultural plants); whereas, N3P3 (minor source) was higher in ornamental plants (40\%) than in other plants $(28.57 \%$ in crops, $12.20 \%$ in wild and $10.53 \%$ in horticultural plants) (Table 1).

Citrus spp., Litchi chinensis, Prunus persica, Psidium guajava, Pyrus communis among horticultural plants; Brassica spp., Cucumis sativus, Cucurbita maxima, Guizotia abyssinica, Helianthus annus, Raphanus sativus and Sesamum indicum among agricultural crops; Callistemon citrinus, Grevillea robusta and Impatiens sp. among ornamental plants and Aesandra butyracea, Bombax ceiba, Dalbergia sissoo, Elaeagnus parvifolia, Engelhardia spicata, Eucalyptus sp., Grewia optiva, Lagerstroemia parviflora, Myrica esculenta, Prunus cerasoides, Rhododendron arboreum, Syzygium cumini and Trifolium repens among wild plants were the important bee floras of the study area as they were identified as the major sources of both nectar and pollen (Appendix 1-4).

The honeydew plants identified were Berberis aristata, Fraxinus floribunda, Juniperus sp., Phyllanthus emblica, Pinus roxburghii, Rubus ellipticus, Saccharum officinarum, Sapium insigne and Syzygium cumini. Honeydew was a less important floral cue compared to pollen and nectar as the honeydew was present in very limited plant species (less than $8 \%$ of the total plants examined) (Table 1). Plant species like Alnus nepalensis, Ricinus communis, Shorghum vulgare and Zea mays were visited by bees only for pollen; whereas, Mentha spicata was visited only for nectar (Appendix 1-4). However, honey from some plants, like Lyonia ovalifolia, according to farmers, is poisonous to human health. Same results were 
Table 1. Nectar and pollen statuses of different plants found in study area.

\begin{tabular}{|c|c|c|c|c|c|c|c|c|c|c|c|c|c|c|c|c|c|c|}
\hline \multirow[t]{2}{*}{ Plants } & \multicolumn{18}{|c|}{ Sources and statuses of pollen and nectar } \\
\hline & N1 & N2 & N3 & P1 & P2 & P3 & $\begin{array}{l}\text { N1 } \\
\text { P1 }\end{array}$ & $\begin{array}{l}\mathrm{N} 2 \\
\mathrm{P} 2\end{array}$ & $\begin{array}{l}\text { N3 } \\
\text { P3 }\end{array}$ & $\begin{array}{l}\text { N1 } \\
\text { P2 }\end{array}$ & $\begin{array}{l}\text { N1 } \\
\text { P3 }\end{array}$ & $\begin{array}{l}\mathrm{N} 2 \\
\mathrm{P} 1\end{array}$ & $\begin{array}{l}\text { N2 } \\
\text { P3 }\end{array}$ & $\begin{array}{l}\text { N3 } \\
\text { P1 }\end{array}$ & $\begin{array}{l}\text { N3 } \\
\text { P2 }\end{array}$ & $\mathrm{H} 1$ & $\mathrm{H} 2$ & H3 \\
\hline $\begin{array}{l}\text { Horticultural } \\
\text { plants (19 species) }\end{array}$ & 11 & 4 & 3 & 13 & 2 & 3 & 11 & 2 & 2 & 0 & 0 & 1 & 1 & 1 & 0 & 1 & 0 & 0 \\
\hline $\begin{array}{l}\text { Crop plants } \\
\text { (42 species) }\end{array}$ & 13 & 10 & 17 & 13 & 11 & 17 & 10 & 8 & 12 & 1 & 2 & 0 & 1 & 1 & 2 & 0 & 0 & 0 \\
\hline $\begin{array}{l}\text { Ornamental plants } \\
\text { (15 species) }\end{array}$ & 5 & 3 & 7 & 3 & 5 & 7 & 2 & 3 & 6 & 2 & 1 & 0 & 0 & 1 & 0 & 0 & 0 & 0 \\
\hline $\begin{array}{l}\text { Wild plants } \\
\text { (82 species) }\end{array}$ & 23 & 35 & 17 & 25 & 35 & 21 & 15 & 22 & 10 & 5 & 3 & 6 & 7 & 2 & 5 & 1 & 6 & 4 \\
\hline $\begin{array}{l}\text { Total plants } \\
\text { (158 species) }\end{array}$ & 52 & 52 & 44 & 54 & 54 & 48 & 38 & 35 & 30 & 8 & 6 & 7 & 9 & 5 & 7 & 2 & 6 & 4 \\
\hline
\end{tabular}

Note: N1 = major nectar source, N2 = medium nectar source, N3 = minor nectar source, $\mathrm{P} 1=$ major pollen source, $\mathrm{P} 2=$ medium pollen source, P3 = minor pollen source, $\mathrm{H} 1$ = major honey dew source, $\mathrm{H} 2$ = medium and H3 minor honey dew source.

also reported by Bista and Shivakoti (2000-2001) and Kafle (1992).

\section{HONEY FLOW AND DEARTH PERIODS}

The period from March to May and then from August to October were the main honey flow periods because most of the plants bloomed in these months and environment was also favorable for bees' activities (Table 2). Among these months too, March-April was the most favorable period for honey production. The plant species Berberis aristata, Bombax ceiba, Brassica spp., Callistemon citrinus, Citrus spp., Mangifera indica, Rubus ellipticus were some of the major sources of honey during these months. The period from November to February (the colder months) was the dearth period i.e. not favorable for the honey bees. The species bloomed during this time were Euphorbia pulcherrima, Fagopyrum esculentum, Solanum tuberosum, Pogostemon glaber, Hypericum spp. and Brassica spp. Similarly, June and July (the rainy months) were also not favorable for the bees (Figure 3). Though relatively more flowers were bloomed during rainy season, due to heavy and continuous rain, bee foraging was found to be limited. Horticultural plants mainly flowered during March-April, crops during July-September, ornamental plants throughout the year (mainly AugustSeptember and April-May), and wild plants during AprilMay. Some ornamental plants like Malvaviscus sp., Salvia sp. and Verbena sp. bloomed throughout year.

\section{Discussion}

Altogether 158 plant species were identified as bee flora in the study area, and they bloomed in different seasons. Out of which, plants having both nectar and pollen with their same status were more than the plants having unequal status of pollen and nectar indicating a positive relationship of the presence of two major floral cues, i.e. nectar and pollen in the flowering plants. Our results indicated that if a plant species is a major source of nectar, it is likely that the same plant species would also be major source of pollen. Horticultural species were more important as sources of nectar and pollens than other categories. Therefore, plantation of horticultural species seems to be more effective than the other kinds of plant species for bee keeping.

March and April has been identified as the main honey flow season. Similarly, the winter season, with low temperature, short sunshine period and availability very few flowering plants, has been identified as the critical dearth period. Study has already revealed that the rainy and cold weather mostly reduces bees' activity (Adhikari 2003, 2010; Kearns and Inouye 1993). However, there were some plants which bloomed during winter, including Pisum sativum, Ipomoea batata and Eupatorium sp. Similarly, Lagerstroemia sp., Impatiens balsamina, Sesamum indicum, Zea mays and many cucurbits bloomed during rainy season.

The inevitable and obligate role of pollination makes it clear that the conservation of pollination systems is an important priority for all (Adhikari 2003). The declining apple 


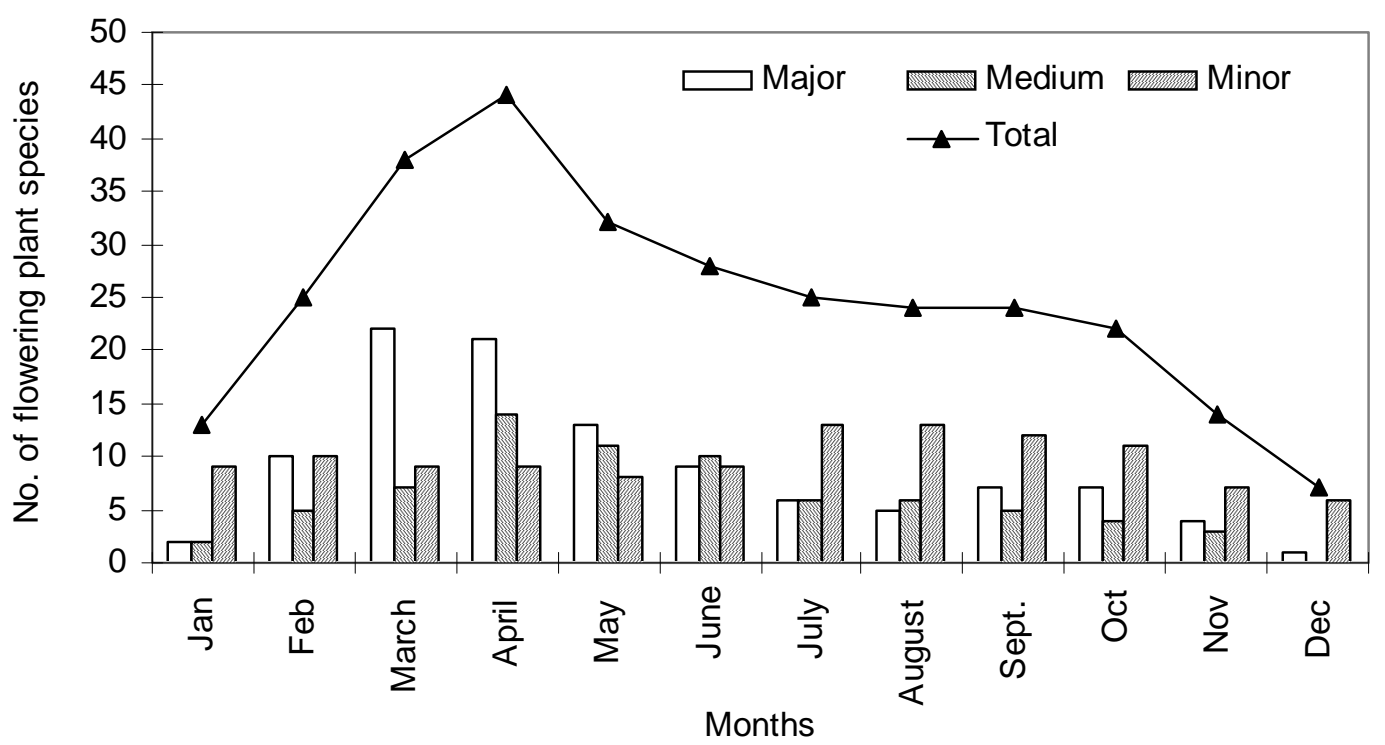

Figure 3. Different plants flowering in different months of the year.

Table 2. Number of species of different categories in bloom during different months.

\begin{tabular}{lcccccccccccc}
\hline Plants & Jan & Feb & Mar & Apr & May & Jun & Jul & Aug & Sep & Oct & Nov & Dec \\
\hline Horticultural plants (fruits) & 3 & 8 & 14 & 11 & 5 & 2 & 1 & 1 & 2 & 2 & 1 & 1 \\
Crops (cereals, vegetables, pulses) & 5 & 12 & 13 & 8 & 6 & 12 & 18 & 14 & 17 & 12 & 9 & 6 \\
Ornamental plants & 4 & 4 & 7 & 9 & 9 & 7 & 7 & 10 & 9 & 6 & 4 & 4 \\
Wild plants & 4 & 16 & 28 & 36 & 34 & 30 & 27 & 25 & 25 & 18 & 11 & 2 \\
Total & 16 & 40 & 62 & 64 & 54 & 51 & 53 & 50 & 53 & 38 & 25 & 13 \\
\hline
\end{tabular}

production in the Hindukush Himalaya has been attributed to the loss of local/wild pollinators and consequently to the inadequate crop pollination (Partap and Partap 2001; Ahmad et al 2002; Adhikari 2003, 2010). Managed/controlled pollination of crops has been a largely neglected part of our agriculture system. By exploring the knowledge about bee flora and conserving them, the production of honey and the agri-products can be increased to a larger amount (Partap 1997). Encouraging farmers for horticultural farming of extremely important bee flora, as reported in this study, can help to increase the socio-economic status of farmers; the more bees, the more honey and fruit production.

The present study has shown that the mid-hills of Central Nepal is rich in bee flora and has great potential for beekeeping as many plants bloomed even in dearth periods. However, the results presented here are only preliminary. In the future studies, the use of sophisticated methods to understand the co-evolution of bees and bee floras, and to measure relative importance of plant species as sources of pollen and nectar would generate more reliable data. Pollination ecology of each plant would give more clear and valid picture of bee flora.

\section{Acknowledgements}

The authors are highly grateful to the local farmers of the study area for sharing their valuable knowledge. Thanks are also due to two anonymous reviewers for their valuable comments on the earlier versions of the manuscript.

\section{References}

Adhikari S. 2003. Floral Phenology and Pollination Ecology of Pedicularis dendrothauma R. R. Mill and D J Allard in Sikles (ACAP) Kaski, Nepal. M.Sc. Thesis, Central Department of Botany, Tribhuvan University, Kathmandu, Nepal. 
Adhikari S. 2010. Floral phenology and pollination ecology of Punica granatum L. in Kathmandu, Nepal. Nepal Journal of Science and Technology 11: 115-124.

Ahmad F., Partap U., Joshi S.R. and Gurung M.B. 2002. Why The Hindu Kush Himalayan (HKH) Region Needs the Native Hive Honeybee Apis cerana? Briefing Paper, International Centre for Integrated Mountain Development (ICIMOD), Kathmandu, Nepal.

Bista S. and Shivakoti C.P. 2000-2001. Honey bee flora at Kabre, Dolakha District. Nepal Agriculture Research Journal 4-5: 18-25.

Costanza R., d’Arge R., de Groot R., Farberk S., Grasso M., Hannon B., Limburg K., Naeem S., O’Neill R.V., Paruleo J., Raskin R.G., Sutton P. and van den Belt M. 1997. The value of the world's ecosystem services and natural capital. Nature 387: 253-260.

DHM 2004. Climatological Records of Nepal. Department of Hydrology and Metrology, Babarmahal, Kathmandu, Nepal.

Joshi S.R. 1999. Physico-chemical and Melisso-palynological Characteristics of Nepalese Honey. Ph.D. Dissertation, University of Agricultural Sciences, Vienna, Austria.

Kafle G.P. 1992. A general survey of bee flora in and around Kathmandu valley. Nepalese Journal of Agriculture 15: 8999.
Kearns C.A. and Inouye D.W. 1993. Techniques for Pollination Biologists. University Press of Colorado, Niwot, Colorado, USA.

Macior L.W. and Ya T. 1997. A preliminary study of the pollination ecology of Pedicularis in the Chinese Himalaya. Plant Species Biology 12: 1-7.

Macior L.W. 1990. Pollination ecology of Pedicularis punctata Decne. (Scrophulariaceae) in the Kasmir Himalaya. Plant Species Biology 5: 215-223.

Mishra R.C., Kumar J. and Gupta J.K. 1989. A new approach to the control of predatory wasps (Vespa spp.) of the honey bees Apis mellifera L. Journal of Apiculture Research 28: 126-131.

NTB 2010. Himalayan Peaks of Nepal. Nepal Tourism Board, Kathmandu, Nepal.

Partap U. 1997. Bee Flora of the Hindukush-Himalayas. Inventory and Management. International Centre for Integrated Mountain Development (ICIMOD), Kathmandu, Nepal.

Partap V. and Partap T. 2001. Declining Apple Production and Worried Himalayan Farmers: Promotion of Honeybees for Pollination. Issues in Mountain Development Vol. 1. International Centre for Integrated Mountain Development (ICIMOD), Kathmandu, Nepal.

Ranabhat N.B. 2010. Beekeeping: Indigenous Practice in the Mid-hills of Nepal. LAP LAMBERT Academic Publishing AG \& Co. KG., Germany. 


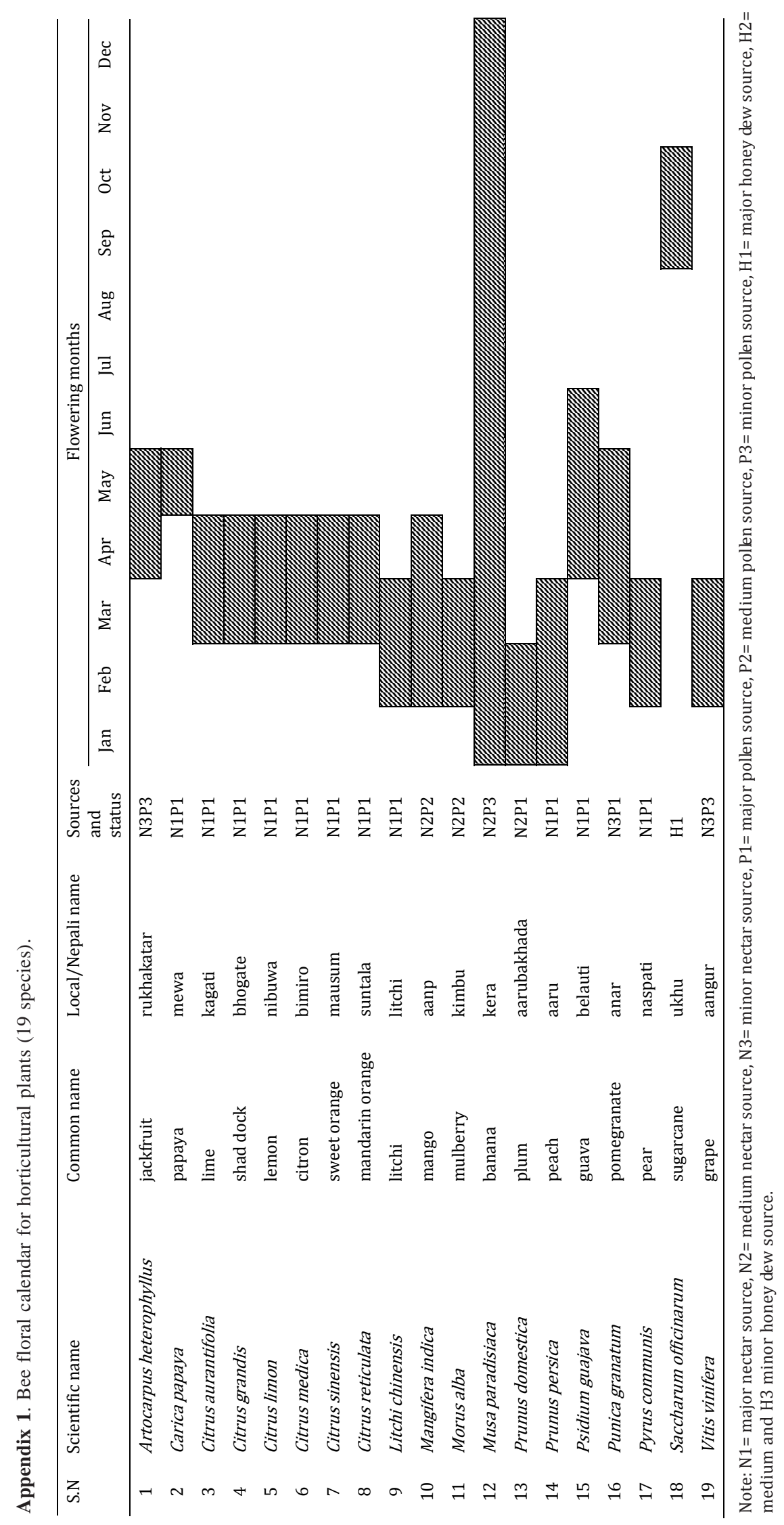

(C) 2011 Central Department of Botany, Tribhuvan University, Botanica Orientalis - Journal of Plant Science (2011) 8: 45-56 


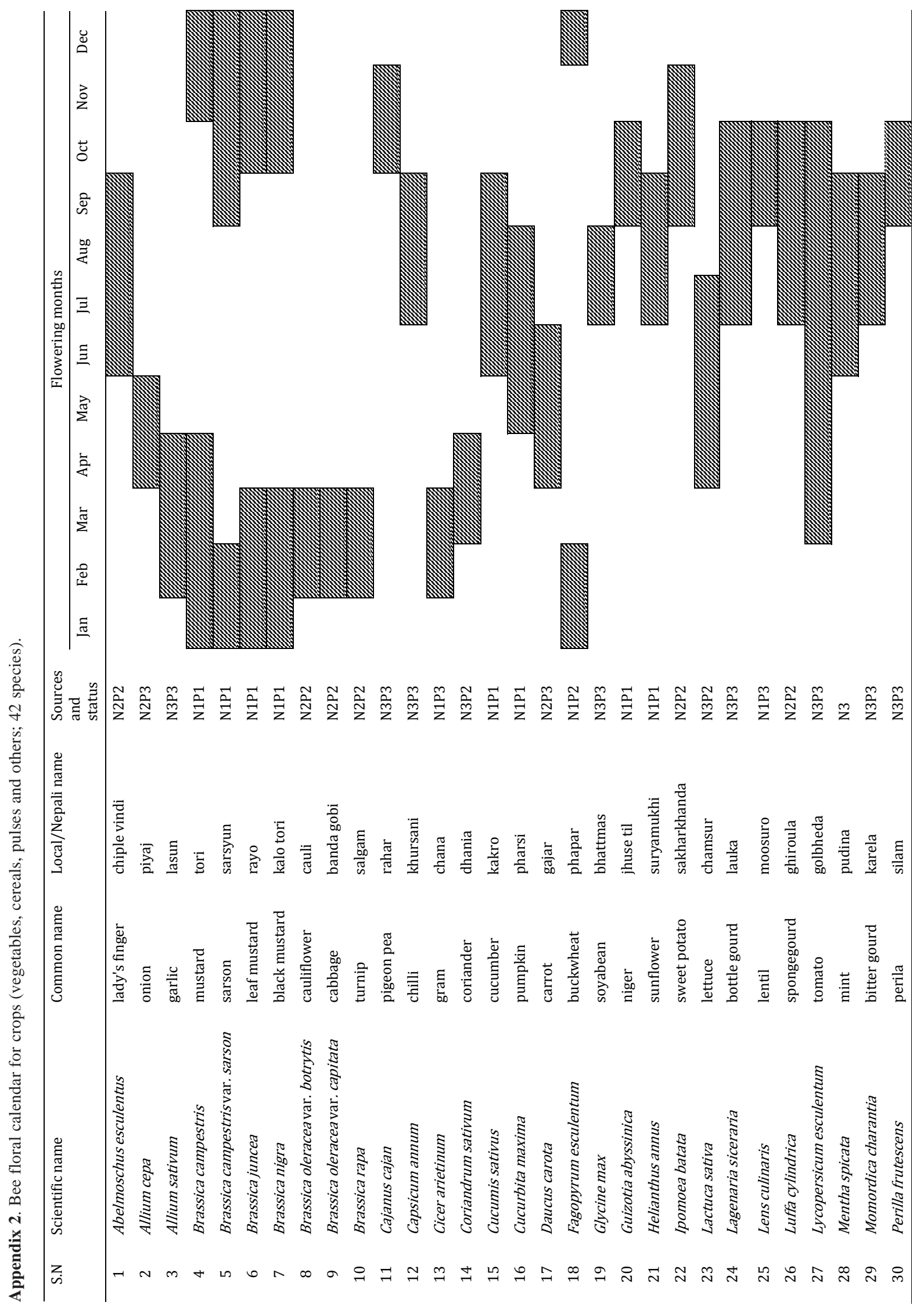




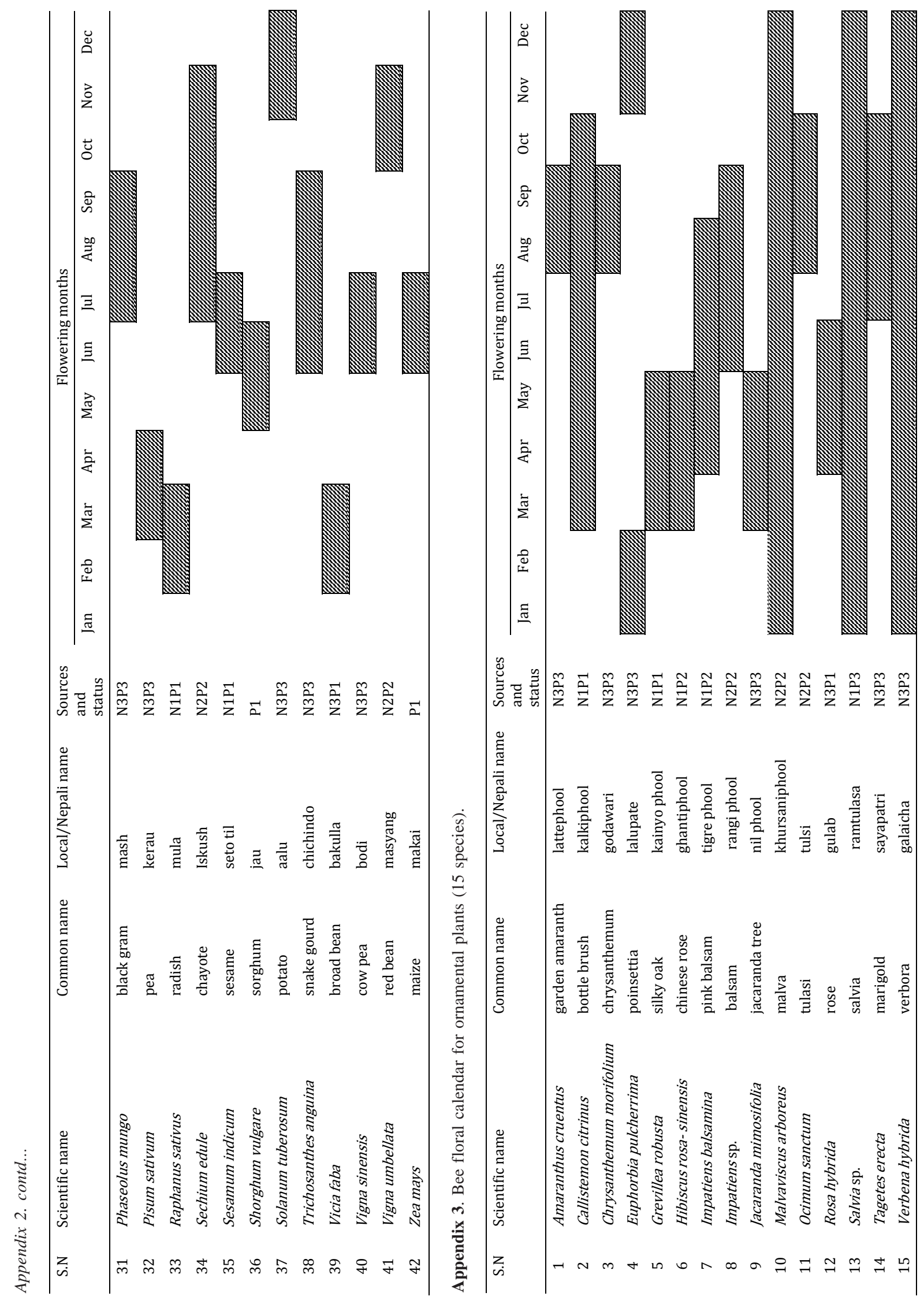



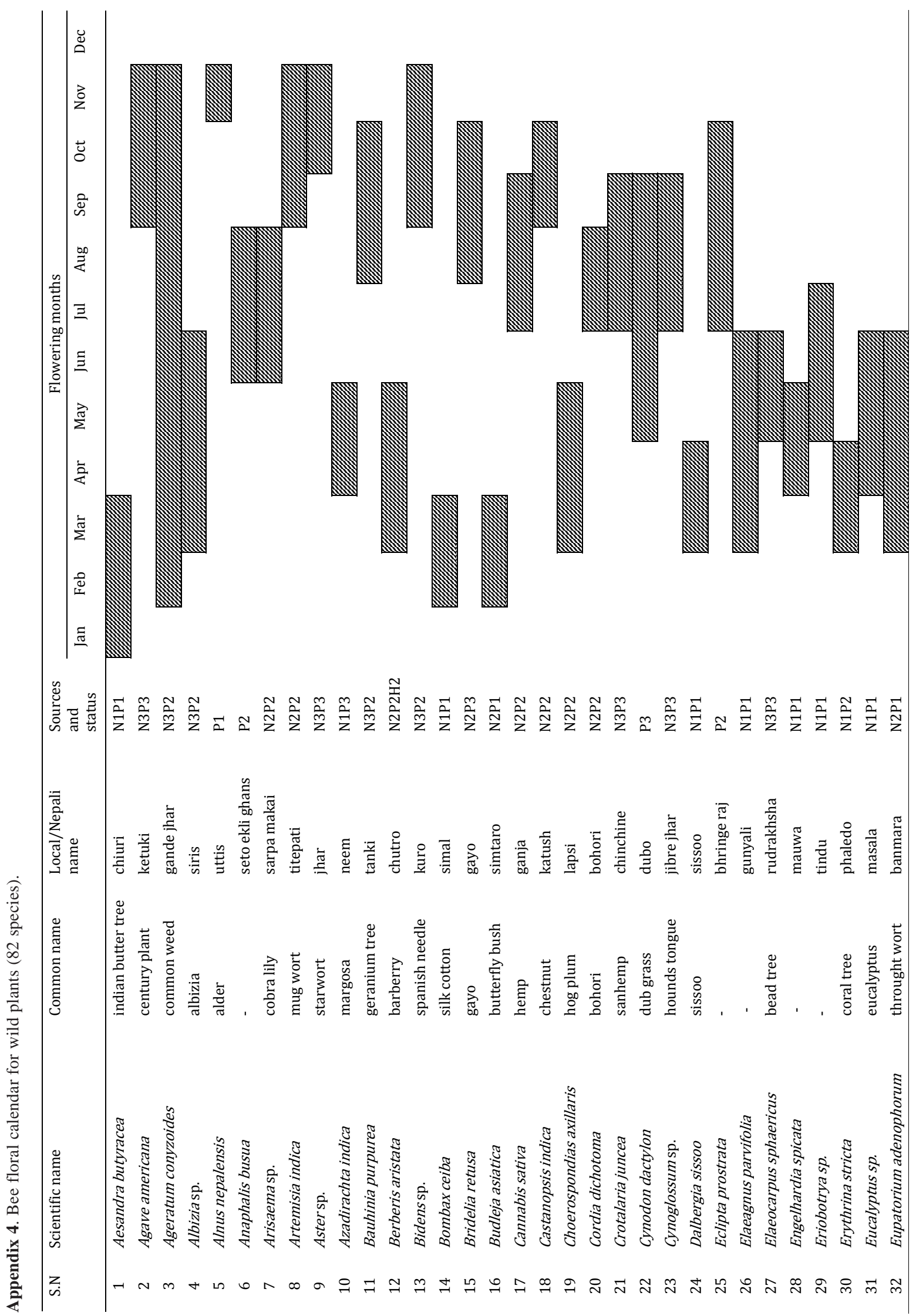


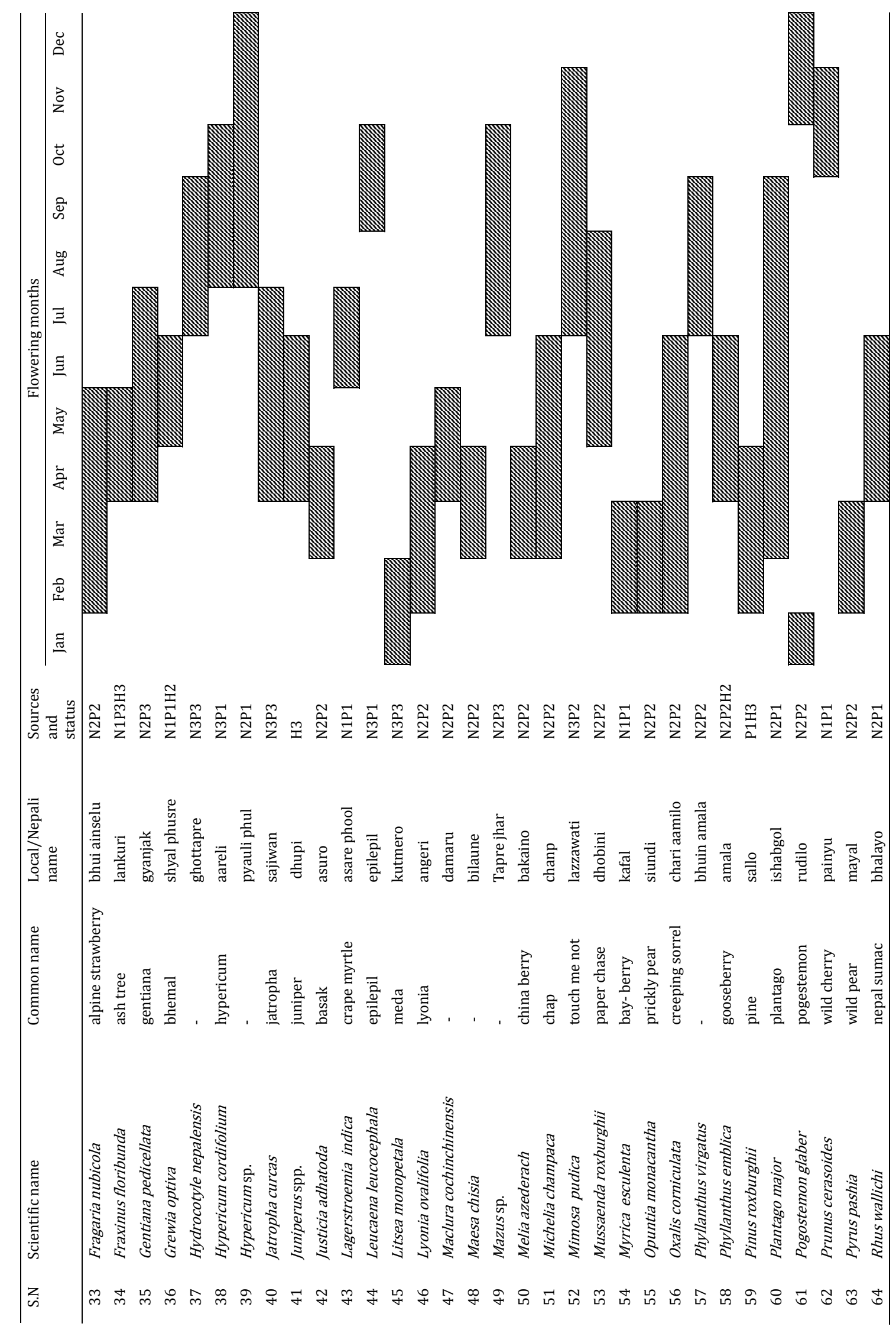




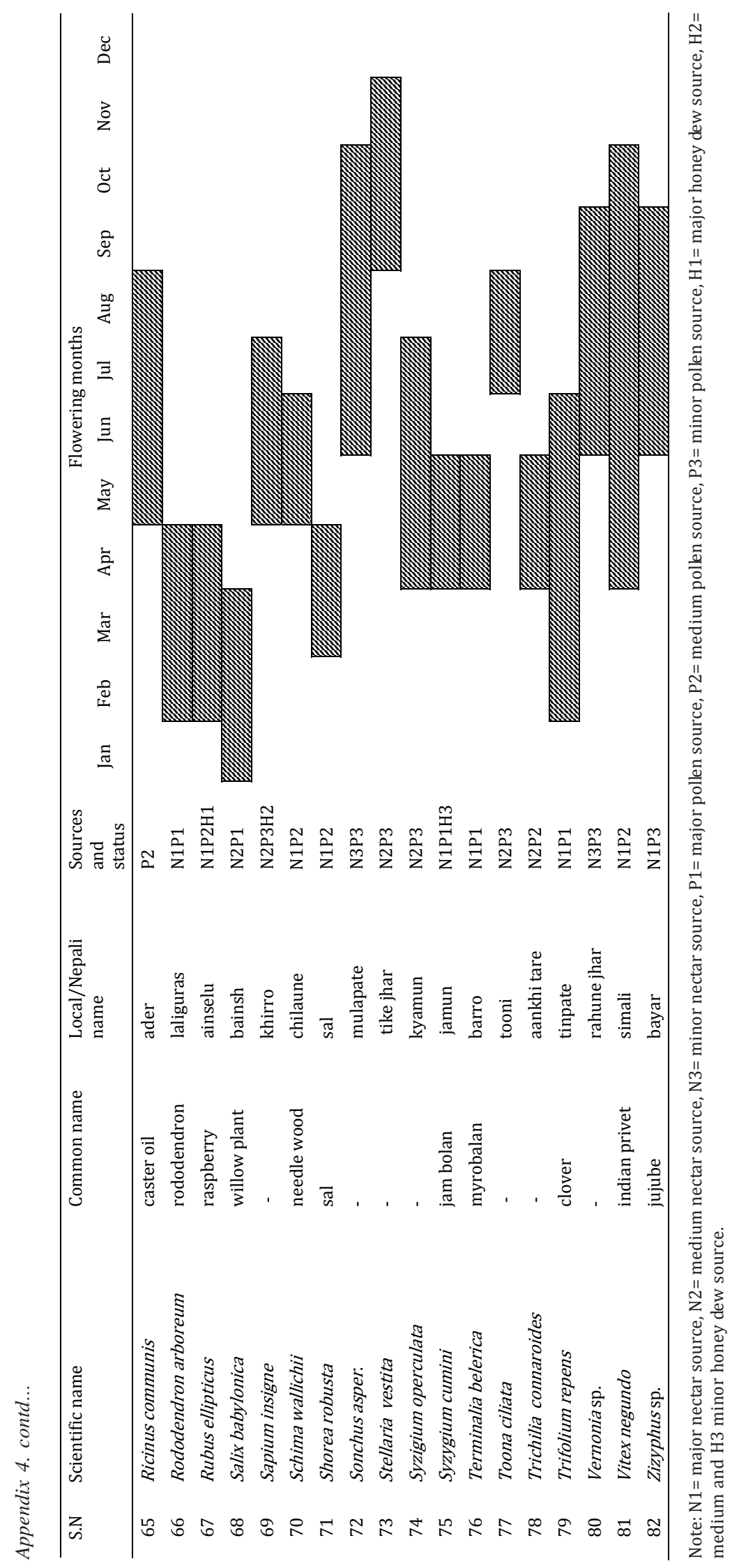

(C) 2011 Central Department of Botany, Tribhuvan University, Botanica Orientalis - Journal of Plant Science (2011) 8: 45-56 